\title{
Underwater light field determined by water constituents in highly turbid water: the case of Taihu lake
}

\author{
Chang-Chun HUANG,${ }^{1 *}$ Yun-Mei LI, ${ }^{1}$ Hao YANG,${ }^{1}$ Qiao WANG, ${ }^{1}$ Jun-Sheng LI, ${ }^{2}$ Xia CHEN ${ }^{1}$ \\ ${ }^{1}$ Key Laboratory of Virtual Geographic Environment, Nanjing Normal University, Ministry of Education, Nanjing 210046, China; \\ ${ }^{2}$ Center for Earth Observation and Digital Earth Chinese Academy of Sciences, Beijing, 100094, China. \\ *Corresponding author: huangchangchun_aaa@163.com
}

\begin{abstract}
The relationships between optical properties and water constituents in highly turbid productive water were studied on the basis of the multiple bio-optical measurements and samplings of water constituents made during five cruises from 2006 to 2008 in Taihu lake. Taihu lake is a high dynamic ratio [(square root of area)/depth] inland shallow lake. The spatial and temporal variation of water constituents and optical properties is significant. The inorganic suspended matter (ISM) has become the primary constituent in Taihu lake: its average percentage can reach $65.21 \%$. The concentration of ISM is highly correlated to the optical properties in Taihu lake due to the sediment resuspension. Consequently, the ISM can be taken into account as an important optically-active constituent in Taihu lake. Resuspended sediments also lead to a poor correlation between scattering optical property and chlorophyll-a concentration $\left(\mathrm{C}_{C h l-a}\right)$. However, empirical relationship between the $\mathrm{C}_{C h l-a}$ and phytoplankton absorption coefficient at $675 \mathrm{~nm}$ is still valid when the package effect is removed. The parameters of linear equation in the present study have slight temporal variation, especially for the relationships between inherent optical properties (IOPS) and concentration of total suspended matter (TSM). The relationship between apparent optical property (AOP) (diffuse attenuation coefficient of particle, $\mathrm{K}_{\text {dbio }}$ ) and ISM has been examined as well. The $\mathrm{K}_{\text {dbio }}$ is strongly affected by ISM, and correlates to it with linear function. The difference between specific diffuse attenuation coefficients of organic $\left[\mathrm{K}_{d O S M}^{*}(\lambda)\right]$ and inorganic $\left[\mathrm{K}_{d I S M}^{*}(\lambda)\right]$ particles is significant. $\mathrm{K}_{d O S M}^{*}(\lambda)$ includes the absorption property of chlorophyll-a (chl-a) at 675 $n m$, which is much higher than that of $\mathrm{K}_{\text {dISM }}^{*}(\lambda)$. This indicates that the attenuation ability of OSM is stronger than that of ISM although the $\mathrm{K}_{\text {dbio }}$ induced by large concentration of ISM is bigger than the $\mathrm{K}_{\text {dbio }}$ induced by small concentration of OSM. Overall, the knowledge of the bio-optical properties obtained in this study extends our understanding of water optics and can be used to predict the optical properties via water constituent concentration, regardless of measurement type (in situ or simulated by hydrodynamic model).
\end{abstract}

Key words: Bio-optical properties, water constituents, diffuse attenuation coefficient, turbid lake.

Received: May 2012. Accepted: July 2012.

\section{INTRODUCTION}

Underwater light field and remote sensing signals are mainly determined by inherent optical properties (IOPs), which are affected by the different physicochemical properties of water constituents (Jerlov, 1976; Morel and Ahn, 1990; Morel and Bricaud, 1991; Morel et al., 2006; Wozniak et al., 1991, 1995; Semovski, 1999). Studies of lake ecosystems and successful application of remote sensing to retrieve the concentrations of water constituents requires accurate determination of the relationships between IOPs and water constituents. Therefore, studies of the biooptical properties of inland lake water are keys to understanding the influence of water constituents on the underwater optical field and stability of the bio-optical algorithm of lake water (Dickey et al., 1993; Bricaud et al., 2002). Many studies on bio-optical properties have been carried out, and indicated that the temporal and spatial variations of bio-optical models are significant (Gordon and Morel, 1983; Loisel and Morel, 1998; Gould et al., 1999; Morel and Maritorena, 2001; Morel and Belanger,
2006; Morel and Claustre, 2007; Morel, 2009). This is due to many factors. For instance, the refractive index and particle size influence the scattering and backscattering coefficients (Sun et al., 2009; Huang et al., 2012), and the package effect influences the phytoplankton absorption coefficients (Le et al., 2009). The relationship between IOPs and the water constituent concentration can be considered in terms of the relationship between chlorophyll-a concentration $\left(C_{\mathrm{Chl-a}}\right)$ and phytoplankton absorption (or backscattering coefficient). This is because of its role in ocean-color and of primary production estimation (Smith et al., 1984, 1996; Platt, 1986; Platt and Sathyendranath, 1988; Platt et al., 1990, 1991; Siegel et al., 2001).

However, resuspended sediments induced by waves and underset significantly modify the underwater light field and the principal optically-active constituents in inland shallow lakes. Minerals become the main optically-active constituents when sediments are resuspended. IOPs are fundamental parameters of water optical properties. Indeed, not only do they respond to physicochemical properties of the 
water constituents, but they also directly determine the underwater light field and remote sensing reflectance. Thus, more attention should be paid to the bio-optical relationships between IOPs and minerals in highly turbid inland water, where minerals are the main optically-active constituents. This is particularly true for shallow eutrophic lakes in monsoon areas, such as Taihu lake (Qin et al., 2004).

In the current study, the bio-optical relationships between IOPs (i.e. absorption, scattering, backscattering, and attenuation) and chlorophyll-a concentrations $\left(C_{\text {chl-a }}\right)$ are reexamined. The concentration of inorganic suspended matter (ISM) is taken into account as an optically-active component more important than chlorophyll-a (chl-a) in Taihu lake. The bio-optical property of Taihu lake is discussed by touching upon the relationships between its IOPs, diffuse attenuation coefficients, and ISM.

The purpose of this study is: i) to establish the bio-optical relationships between IOPs and ISM; and ii) to determine the photosynthetically active radiation (PAR) capacity of ISM and OSM in a high dynamic ratio [(square root of area)/depth] inland shallow lake. The biooptical relationships between IOPs and ISM could be used to quantify the influence of water constituents changed by hydrodynamics on the underwater light field and on the remote sensing signals of lake water. Furthermore, they could also be used to predict the optical properties and underwater light field via water constituents concentration, irrespective of measurement type (in situ or simulated by hydrodynamic model).

\section{METHODS}

\section{Study area and sample collection}

Taihu lake is a typical inland shallow eutrophic lake. It is located in the East Asia Monsoon Area (EAMA), precisely in the Yangtze river delta. The inhabitants of the surrounding cities of $\mathrm{WuXi}$, SuZhou, and HuZhou regularly drink its water. The mean depth of Taihu lake is $1.9 \mathrm{~m}$ and the area is $2338 \mathrm{~km}^{2}$ (Qin et al., 2004). The dynamic ratio [(square root of area)/depth] can reach 25.4. Thus, sediment in Taihu lake is extremely easy to resuspend, as demonstrated in the study by Bachmann et al. (2000).

Water sample collection and optical measurements were carried out in Taihu lake during five cruises in August 2006 (15 points in Meiliang Bay, no backscattering and scattering data), November 2006 (69 points in the whole Taihu lake), March 2007 (15 points in Meiliang Bay), November 2007 and November 2008 (69 points in the whole Taihu lake for both months) (Fig. 1).

\section{Water constituents sample analysis}

Water samples (placed inside 6-litre polyethylene bottles) were collected from all stations just below the surface $(20 \mathrm{~cm})$. Total suspended matter (TSM) was obtained by measuring the difference in weight of pre-combusted $\left(450^{\circ} \mathrm{C}\right.$ for $\left.4 \mathrm{~h}\right)$ and dried $\left(105^{\circ} \mathrm{C}\right.$ for $\left.4 \mathrm{~h}\right) 0.7-\mu \mathrm{m}$ Whatman GF/F glass fibre filters before and after filtration of whole-water field samples. The filters were re-combusted at $450^{\circ} \mathrm{C}$ for $4 \mathrm{~h}$ to remove the weight of organic sus-

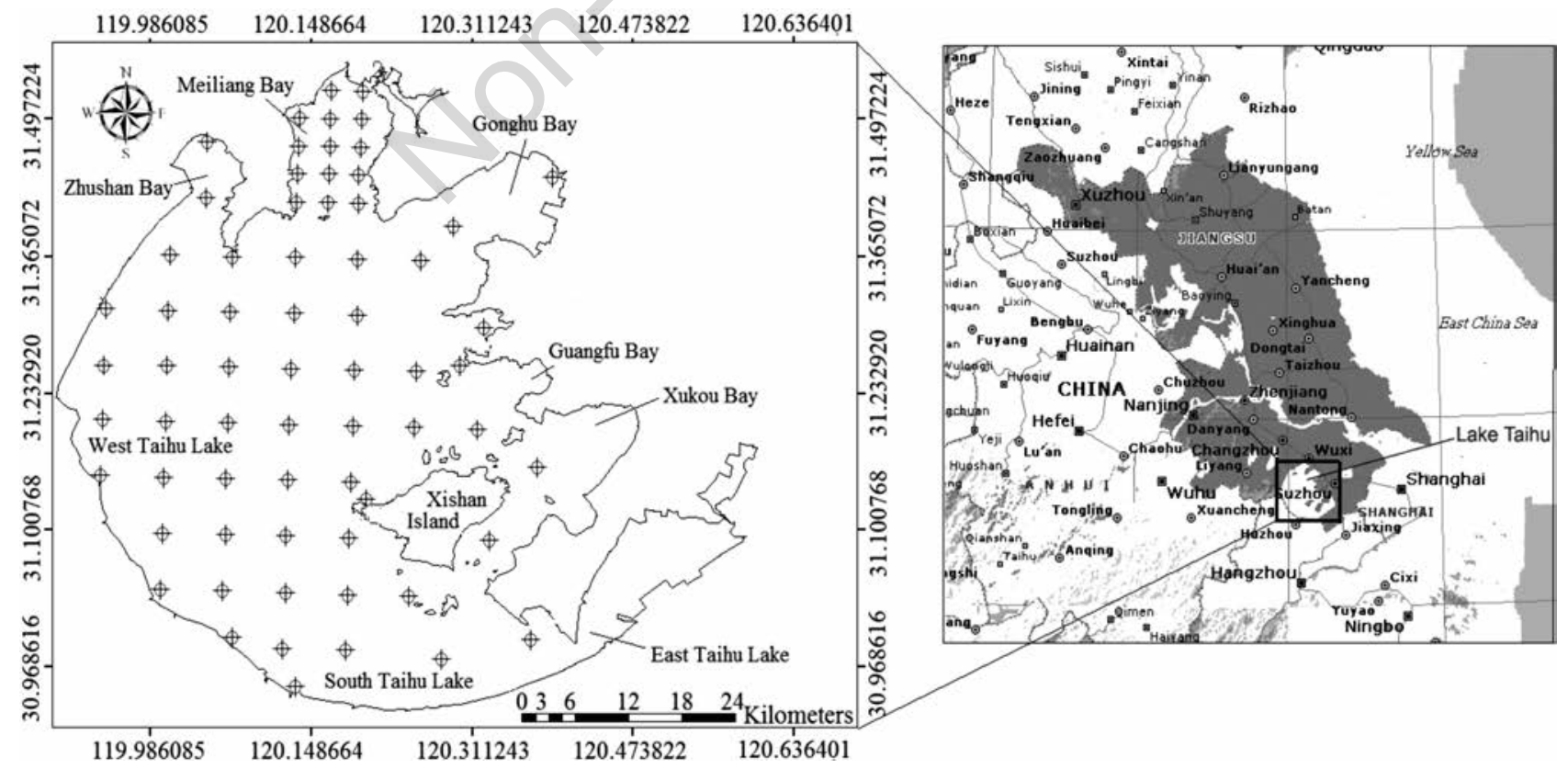

Fig. 1. Distribution of sample stations in the study area (in the top right corner the position of Taihu lake in JiangSu province, China). 
pended matter (OSM), and weighed again to obtain ISM (Pegau et al., 2003). On the other hand, OSM was obtained by subtracting ISM from TSM. Samples of chl-a were filtered on Whatman GF/C filters. Chl-a was extracted with ethanol $(90 \%)$ at $80^{\circ} \mathrm{C}$ and analysed spectrophotometrically at 750 and $665 \mathrm{~nm}$, with correction for phaeopigments (Chen et al., 2006). Detailed information on water samples is provided in Tab. 1.

\section{Optical property measurements in situ}

\section{Inherent optical property measurements}

The spectral absorption $a(\lambda)$ and beam attenuation $c(\lambda)$ coefficients of the particles were measured $20 \mathrm{~cm}$ below the water surface using an AC-S profiler (WET Labs Inc., Philomath, OR, USA). The instrument provided an 85wavelength output over approximately 400-760 nm.

The AC-S profiler was calibrated with pure water and air to ensure that its performance was within factory specifications $\left( \pm 0.005 \mathrm{~m}^{-1}\right)$. The change in absorption due to temperature and salinity was corrected according to Sullivan et al. (2006):

$a_{\mathrm{mts}}(\lambda)=a_{\mathrm{m}}(\lambda)-\left[\psi_{\mathrm{t}}\left(t-t_{\mathrm{r}}\right)+\psi_{\mathrm{s}}\left(S-S_{\mathrm{r}}\right)\right]$

where

$a_{\mathrm{mts}}(\lambda)$ is the corrected absorption;

$a_{\mathrm{m}}(\lambda)$ is the measured raw data;

$\psi_{\mathrm{t}}$ and $\psi_{\mathrm{s}}$ are the corrected parameters for temperature and salinity;

$t$ and $S$ are temperature and salinity measured in situ;

$t_{\mathrm{r}}$ and $S_{\mathrm{r}}$ indicate the reference temperature and salinity.

The influence of salinity was ignored because Taihu lake is a fresh water lake.

The absorption was corrected for scattering errors according to Zaneveld et al. (1994):

$a_{\mathrm{p}+\mathrm{g}}(\lambda)=a_{\mathrm{t}}(\lambda)-a_{\mathrm{w}}(\lambda)=a_{\mathrm{mts}}(\lambda)-a_{\mathrm{mts}}\left(\lambda_{\text {ref }}\right)$

where $a_{\mathrm{p}+\mathrm{g}}(\lambda)$ is the absorption coefficient of dissolved matter; $a_{\mathrm{t}}(\lambda)$ is the total absorption coefficient;

$a_{\mathrm{w}}(\lambda)$ is the absorption coefficient of pure water;

$a_{\mathrm{mts}}\left(\lambda_{\text {ref }}\right)$ is the corrected absorption at reference wavelength $\left(\lambda_{\text {ref }}=715 \mathrm{~nm}\right)$.

The scattering coefficient of coloured dissolved organic matter (CDOM) was ignored during the calculation of scattering coefficient of particle $\left[b_{\mathrm{p}}(\lambda)\right]$. The term $b_{\mathrm{p}}(\lambda)$ could be calculated by following this formula (Moore et al., 2004):

$b_{\mathrm{p}}(\lambda)=c_{\mathrm{p}+\mathrm{g}}(\lambda)-a_{\mathrm{p}+\mathrm{g}}(\lambda)$

where

$c_{\mathrm{p}+\mathrm{g}}(\lambda)$ is the attenuation and absorption coefficients of the particulate;

$a_{\mathrm{p}+\mathrm{g}}(\lambda)$ is the attenuation and absorption coefficients of the dissolved matter.

The backscattering coefficient of particle $b_{\mathrm{bp}}(\lambda)$ was measured $20 \mathrm{~cm}$ below the water surface using a BB9 profiler (WET Labs Inc., Philomath, OR, USA). The BB9 profiler measures scattering at a single angle in a backward direction $\left(117^{\circ}\right)$ at nine wavelengths $(412,440,488$, 510, 532, 595, 660, 676, and $715 \mathrm{~nm})$.

For the population of photons scattered within the remote sample in front of the sensor, there is attenuation along the path from the light source through the sample volume to the detector. This result, however, underestimates the true volume scattering in the hydrosol. Consequently, a weighted function was used to calibrate this attenuation effect.

$\beta\left(117^{\circ}, \lambda\right)^{*}=$ Scale Factor $(\lambda) \cdot$

$[\operatorname{Output}(\lambda)-\operatorname{Dark} \operatorname{Counts}(\lambda)]$

where

$\beta\left(117^{\circ}, \lambda\right)^{*}$ is the raw total volume scattering coefficient; Scale $\operatorname{Factor}(\lambda)$ is the calibrated scale factor;

$\operatorname{Output}(\lambda)$ is the measured signal output of the scattering metre;

Tab. 1. Overview on the data set.

\begin{tabular}{llcccc}
\hline Date & $\mathrm{N}$ & $C_{\text {chl-a }}\left(\mathrm{ugL}^{-1}\right)$ & TSM $\left(\mathrm{mgL}^{-1}\right)$ & $\mathrm{ISM}\left(\mathrm{mgL}^{-1}\right)$ & $\left.\mathrm{OSM}_{(\mathrm{mgL}}^{-1}\right)$ \\
\hline $2006-08$ & 15 & $32.00-476.03$ & $15.93-91.33$ & $3.53-59.07$ & $11.47-62.27$ \\
$2006-11$ & 64 & $0.28-216.56^{*}$ & $6.47-143.47$ & $2.47-70.40$ & $3.93-118.67$ \\
$2007-03$ & 15 & $0.96-82.23$ & $12.67-108.33$ & $7.33-94.87$ & $5.33-13.47$ \\
$2007-11$ & 66 & $1.26-130.72$ & $4.76-233.33$ & $2.60-195.20$ & $2.16-38.13$ \\
$2008-11$ & 68 & $2.98-79.80$ & $6.47-265.20$ & $2.67-244.5$ & $4.25-39.33$ \\
\hline
\end{tabular}

$N$, number of collection points; $\mathrm{C}_{\text {chl-a }}$ chlorophyll-a concentration; TSM, total suspended matter; ISM, inorganic suspended matter; OSM, organic suspended matter; *, removed sample points with anomaly data. However, it should be declared that some anomalous data was removed because of floating algae and beyond the measurement range of instrument. 
Dark Counts $(\lambda)$ is the signal obtained by covering the detector with black tape and submersing the sensor in water; Both Scale Factor $(\lambda)$ and Dark Counts $(\lambda)$ were provided in the scattering metre calibration sheet for different wavelengths by WET Labs.

After the scaling factor was calibrated, only the absorption of the incident beam required correction. The calculated raw total volume scattering coefficient $\left[\beta\left(117^{\circ}\right.\right.$, $\left.\lambda)^{*}\right]$ at a given value of absorption coefficient was corrected to zero absorption:

$\beta\left(117^{\circ}, \lambda\right)=\beta\left(117^{\circ}, \lambda\right) \cdot \mathrm{e}^{[0.0391 \cdot \mathrm{a}(\lambda)]}$

where

$\beta\left(117^{\circ}, \lambda\right)$ is the corrected total volume scattering coefficient $\left(\right.$ in $\left.\mathrm{m}^{-1} \mathrm{sr}^{-1}\right)$;

$a(\lambda)$ is the corresponding total absorption coefficient that can be obtained using an AC-S profiler.

The particulate volume scattering coefficient $\left[\beta_{\mathrm{p}}\left(117^{\circ}\right.\right.$, $\lambda)$ ] was obtained by subtracting the volume scattering coefficient of pure water from $\beta\left(117^{\circ}, \lambda\right)$ (Morel, 1974), and $b_{\mathrm{bp}}(\lambda)$ was calculated using equation (6) with an uncertainty of $4 \%$ (Boss et al., 2001):

$b_{\mathrm{bp}}(\lambda)=2 \cdot \pi \cdot X_{\mathrm{p}} \cdot \beta_{\mathrm{p}}\left(117^{\circ}, \lambda\right)\left(X_{\mathrm{p}}=1.18\right)$

where

$X_{\mathrm{p}}$ is a parameter determined from measurements of the volume scattering coefficient with a high angular resolution in various types of water (Boss et al., 2001).

\section{Downward irradiance measurements}

The spectra of downward irradiance $\left[E_{\mathrm{d}}(\lambda)\right]$ were measured at discrete depths $(20,40,60,80,100$, and 120 $\mathrm{cm}$ ) with RAMSES-ACC-VIS (Trios, Rastede, Germany). The output wavelength range of this instrument covered $320-950 \mathrm{~nm}$, with a channel width of approximately 3.3 $\mathrm{nm}$. The detection accuracy was better than $6 \%$ (depending on the spectral range). The downward irradiance obtained at different depths $\mathrm{z}\left[E_{\mathrm{d}}(\mathrm{z}, \lambda)\right]$, was corrected for the slight shift in incoming solar radiation (monitored on the deck) during the experiment. All optical measurements in the current study were performed under sunny and steady conditions. The influence of ship shadow was avoided by using a long crane operated from the stern and oriented in the direction of the sun. The surface wave influence was offset using the method provided by Zaneveld et al. (2001).

$E_{\mathrm{d}}(\mathrm{z}, \lambda)$ spectra, corresponding to the same incident radiation at the same sites, were used to calculate the diffuse attenuation coefficient of the downward irradiance $K_{\mathrm{d}}(\lambda)$ (Smith and Baker, 1981; Darecki and Stramski, 2004):

$$
K_{\mathrm{d}}(\lambda)=-\frac{1}{z-z_{\mathrm{r}}} \ln \left(\frac{E_{\mathrm{d}}(z, \lambda)}{E_{\mathrm{d}}\left(z_{\mathrm{r}}, \lambda\right)}\right)=K_{\mathrm{dw}}(\lambda)+K_{\text {dbio }}(\lambda) \quad \text { (eq. 7) }
$$

where

$\mathrm{z}$ and $\mathrm{z}_{\mathrm{r}}$ are depth and reference depth $\mathrm{z}$;

1 is one (number);

$\ln$ is Napierian Logarithm operation

$E_{\mathrm{d}}(\mathrm{z}, \lambda)$ is the downward irradiance at depth $\mathrm{z}$;

$E_{\mathrm{d}}\left(\mathrm{z}_{\mathrm{r}}, \lambda\right)$ is the downward irradiance at the reference depth $\mathrm{Z}_{\mathrm{r}}$;

$K_{\mathrm{dw}}(\lambda)$ is the diffuse attenuation coefficient of pure water; $K_{\text {dbio }}(\lambda)$ is the diffuse attenuation coefficient except the pure water at wavelength $\lambda$.

$K_{\mathrm{dw}}(\lambda)$ can be expressed as $\left[a_{\mathrm{w}}(\lambda)+b_{\mathrm{bw}}(\lambda)\right] /(0.017 /$ $0.0194)$, where $a_{\mathrm{w}}(\lambda)$ and $b_{\mathrm{bw}}(\lambda)$ are absorption and backscattering coefficients of pure water, respectively. The sum of $a_{\mathrm{w}}(480)$ and $b_{\mathrm{bw}}(480)$ was 0.017 (Pope and Fry, 1997), and $K_{\mathrm{dw}}(480)$ was 0.0194 , as estimated by Baker and Smith (1982). After the diffuse attenuation coefficient for pure water $\left[K_{\mathrm{dw}}(\lambda)\right]$ was subtracted from $K_{\mathrm{d}}$, the $K_{\text {dbio }}$ was obtained.

\section{Absorption measurements in laboratory \\ Total particulate absorption measurements}

The quantitative filter technique (QFT) method (Yentsch, 1962; Mitchell and Kiefer, 1988; Mitchell, 1990 ) was used to quantify the total particle absorption $\left[a_{\mathrm{p}}(\lambda)\right]$. Water samples $(100-200 \mathrm{~mL})$ were filtered through a $47-\mathrm{mm}$ diameter Whatman fiberglass GF/F filter under a low vacuum pressure. If too thick, the water samples were first diluted to ensure that the measured optical density of particulate matter was less than 0.4 . Absorption spectra were recorded every $1 \mathrm{~nm}$ from 350 to $800 \mathrm{~nm}$ using a Shimadzu UV-2550PC UV-Vis spectrophotometer (Shimadzu Corporation, Kyoto, Japan). The optical density of the sample filters $\left(O D_{f}\right)$ at $750 \mathrm{~nm}$ was adjusted to zero. Subsequently, the path length amplification factor $(\beta)$, which was the increased path-length of light due to multi-scattering in the filter, had to be corrected (Mitchell and Keifer, 1984; Hoepffner and Sathyendranath, 1992, 1993; Cleveland and Weidemann, 1993; Arbones et al., 1996). The corrected optical density $\left(O D_{\mathrm{s}}\right)$ of the sample filters was calculated as follows:

$$
O D_{s}=A O D_{f}+B O D_{f}^{2} \quad O D_{f} \leq 0.4
$$

where

$A$ and $B$ are empirical coefficients. In the current study, they were set to 0.378 and 0.532 according to Zhang 
(2009). The absorption coefficients of particle $a_{p}(\lambda)$ were calculated according to Cleveland and Weidemann (1993):

$a_{\mathrm{p}}(\lambda)=2.303 O D_{s}(\lambda) \cdot S / V \mathrm{R}$

where

2.303 is the factor used to convert the base 10 to a natural logarithm;

$O D_{\mathrm{s}}(\lambda)$ is the corrected optical density at wavelength $(\lambda)$;

$S$ is the filter clearance area;

$V$ is the filtered volume;

$\mathrm{R}$ is semidiameter of fiberglass $\mathrm{GF} / \mathrm{F}$ filter.

\section{Non-pigment particulate absorption measurements}

Pigment in the water samples was removed using $0.1 \%$ sodium hypochlorite $(\mathrm{NaClO})$ (Mueller, 2003). The absorption peak of chl-a at $675 \mathrm{~nm}$ was examined to determine whether the pigment had been removed completely. If an absorption peak existed at this wavelength, some pigment remained in the water. This process was repeated until the peak value disappeared. Then, the absorption spectra of the bleached water samples were measured again to obtain the absorption coefficient of non-pigment particles $a_{\mathrm{NAP}}(\lambda)$ by using the same method used for total particulate absorption.

\section{Pigment particulate absorption measurements}

The absorption coefficient of pigment $a_{\mathrm{ph}}(\lambda)$ was obtained by subtracting the absorption coefficient of nonpigment particles $a_{\mathrm{NAP}}(\lambda)$ from the absorption coefficient of particle $a_{p}(\lambda)$ :

$a_{\mathrm{ph}}(\lambda)=a_{\mathrm{p}}(\lambda)-a_{\mathrm{NAP}}(\lambda)$

\section{Colored dissolved organic matter absorption measurements}

Water samples were collected in $2 \mathrm{~L}$ acid-cleaned plastic bottles and held in an icebox while they were in the field. Water samples were first filtered through a 47 $\mathrm{mm}$ diameter Whatman fiberglass GF/F filter with 0.70 $\mu \mathrm{m}$ pores, and then refiltered through a $25 \mathrm{~mm}$ diameter Millipore filter (Millipore Corporation, Billerica, MA, USA) with $0.22 \mu \mathrm{m}$ pores. The absorption spectra of the filtered water were measured between 240 and $800 \mathrm{~nm}$ at $1 \mathrm{~nm}$ intervals using a Shimadzu UV-2550PC Uv-Vis spectrophotometer (Shimadzu Corporation, Kyoto, Japan) with a $1 \times 4 \mathrm{~cm}$ quartz cuvette, where Milli-Q water (Millipore Corporation, Billerica, MA, USA) was used as the reference. The absorption coefficient of CDOM was obtained using the following equation (Bricaud et al., 1981):
$a_{\mathrm{CDOM}}\left(\lambda^{\prime}\right)=2.303 D(\lambda) / r$

where

$a_{\mathrm{CDOM}}\left(\lambda^{\prime}\right)$ is the uncorrected CDOM absorption coefficient at wavelength $\lambda$;

2.303 is the factor used to convert the base 10 to a natural logarithm;

$D(\lambda)$ is the optical density at wavelength $\lambda$;

$r$ is the cuvette light path length in metre.

The absorption coefficient was corrected by backscattering small particles and colloids that had passed through the filters using the following equation (Bricaud et al., 1981; Green and Blough, 1994; Keith et al., 2002):

$a_{\mathrm{CDOM}}(\lambda)=a_{\mathrm{CDOM}}\left(\lambda^{\prime}\right)-a_{\mathrm{CDOM}}\left(750^{\prime}\right) \lambda / 750$

where

$a_{\text {CDOM }}(\lambda)$ is the corrected absorption coefficient at a given wavelength $(\lambda)$;

$a_{\text {CDOM }}\left(\lambda^{\prime}\right)$ is the uncorrected CDOM absorption coefficient at wavelength $\lambda$;

$a_{\mathrm{CDOM}}\left(750^{\prime}\right)$ is the uncorrected absorption coefficient at $750 \mathrm{~nm}$.

\section{RESULTS AND ANALYSIS}

\section{Spatial and temporal variation of water inherent optical properties}

Significant spatial and temporal variations of optical properties were found in Taihu lake. The range of the IOPs and the parameters associated with them for each water constituent are listed in Tab. 2. On the whole, the data range of IOPs and the parameters is very wide and the difference among time series is very big. The scattering coefficient related to the concentration of TSM in November 2007 and 2008 is much bigger than that recorded in November 2006 and March 2007. The backscattering coefficient in March 2007 was grouped in a value area bigger than other time series data. This is because the percentage of ISM is much higher, although in March 2007 TSM is not much bigger than in other time series data. The backscattering ratio $\left[B(\lambda)=b_{\mathrm{b}}(\lambda) / b(\lambda)\right]$ can be used as an indicator of the ratio between ISM and OSM (Jerlov, 1976; Aas, 1981; Twardowski et al., 2001). A high backscattering ratio corresponds with a high percentage of ISM (i.e. high concentration of ISM), and $B$ should linearly correlate with ISM/OSM. However, the multi-scattering effect restrains the covariation of $\mathrm{B}$ and ISM in high ISM concentrations. Consequently, a significant logarithmic relationship between $B$ and ISM/OSM was found in this study, except for the data obtained in November 2006 (November 2008: $R^{2}=0.6216, \mathrm{P}<0.001$; November 2007: 
$R^{2}=0.5084, \mathrm{P}<0.001$; March 2007: $R^{2}=0.4398, \mathrm{P}<0.005$; November 2006: $\left.R^{2}=0.1354, \mathrm{P}<0.1\right)$.

The variations of scattering and attenuation coefficients were given not only by the values, but also by the spectral shape [IOPs decrease with wavelength by power law exponent, namely, $\left.\operatorname{IOP}(\lambda)=\operatorname{IOP}\left(\lambda_{0}\right)\left(\lambda / \lambda_{0}\right)^{S_{\text {Iop }}}\right]$. The wavelength dependence of the scattering and attenuation coefficients is significant. The particle size distribution of the water constituents can be traced by the spectral shape of the attenuation coefficients $\left(S_{\mathrm{c}}\right)$ (Boss and Pegau, 2001). Small-sized particles lead to high $S_{\mathrm{c}}$. The largest value of $S_{\mathrm{c}}$ was found in March 2007, followed by November 2008 , and November 2006 . The $S_{\mathrm{c}}$ in November 2007 was similar to that in November 2006. The spectral shape of the scattering coefficient $\left(S_{\mathrm{b}}\right)$ in the current study was beyond the range of those inprevious studies. $S_{\mathrm{b}}$ in Taihu lake was steeper than -0.6 (Morel et al., 2006) and -0.48 (Snyder et al., 2008), but much smoother than -0.93 (Bernard et al., 2001). Small $S_{\mathrm{b}}$ indicates high absorption of CDOM and non-pigments at short wavelengths (this is the primary influencing factor), and relatively high scattering at long wavelengths (such as that in November 2006). The absorption values of CDOM and non-pigments in March 2007, November 2007, and November 2008 were smaller than that in November 2006. On the contrary, $S_{\mathrm{b}}$ values in March 2007, November 2007, and November 2008 were steeper than that in November 2006. The spectral shape of the backscattering coefficient $\left(S_{\mathrm{bb}}\right)$ in Taihu lake was much steeper than the values of -1.15 (Song and Tang, 2006) and $-0.94 \pm 0.21$ (Snyder et al., 2008) found in ocean water because of the high backscattering property of small particles at short wavelengths. Tab. 2 shows the range of $S_{\mathrm{c}}, S_{\mathrm{b}}$, and $S_{\mathrm{bb}}$ at each time series.

\section{Relationship between inherent optical properties and chlorophyll-a concentration}

Fig. 2 provides the attenuation coefficients at $440 \mathrm{~nm}$ $[c(440 \mathrm{~nm})]$, the absorption coefficients at $677 \mathrm{~nm}$ $\left[a_{\text {Total }}(677 \mathrm{~nm})\right]$, and the scattering $[b(532 \mathrm{~nm})]$ and backscattering coefficients at $532 \mathrm{~nm}\left[b_{\mathrm{b}}(532 \mathrm{~nm})\right]$ of particles (pure water absorption and scattering coefficients were subtracted $(\mathrm{N}=222)$ in comparison with the concentration of chl-a. A poor relationship between IOPs and chla was found (Fig. 2A-D), indicating that chl-a may not be the main optically-active constituent in Taihu lake. Moreover, the high absorption of non-pigments at short wavelengths caused the correlation between $c(440 \mathrm{~nm})$ and chl-a to become significantly low.

Carder et al. (1991) suggested that the chl-a dependence of the $a_{\mathrm{ph}}$ could differ between regions and times. In the current study, the relationship between $a_{\mathrm{ph}}(675 \mathrm{~nm})$ and chl-a was compared before and after the package effect was corrected. The package effect is defined as the ratio of $a_{\mathrm{ph}}$ (the specific absorption coefficient of pigmented cells) to $a_{\text {sol }} *$ (the specific absorption coefficient of the same cellular matter ideally dispersed into the solution). This dimensionless factor [defined as $Q_{\mathrm{a}}{ }^{\text {'] }}$ was theoretically formulated by Morel and Bricaud (1981) and Bricaud and colleagues (1990, 1995, 1998):

$Q_{a}^{\prime}(\lambda)=\frac{3}{2} \frac{1+2 e^{-\rho^{\prime}(\lambda)} / \rho^{\prime}(\lambda)+2\left(e^{-\rho^{\prime}(\lambda)}-1\right) /\left(\rho^{\prime}(\lambda)\right)^{2}}{\rho^{\prime}(\lambda)}($ eq. 13$)$

where

$\rho^{\prime}(\lambda)$ is a process variable, no specify physical significance.

and

Tab. 2. Relative statistical parameters of inherent optical properties.

\begin{tabular}{lcccc}
\hline IOP & $2006-11(\mathrm{~N}=64)$ & $2007-3(\mathrm{~N}=15)$ & $2007-11(\mathrm{~N}=66)$ & $2008-11(\mathrm{~N}=68)$ \\
\hline$C(440 \mathrm{~nm})$ & $5.28 \sim 52.25$ & $12.19 \sim 33.46$ & $6.72 \sim 67.54$ & $3.52 \sim 64.56$ \\
$b(440 \mathrm{~nm})$ & $3.85 \sim 42.90$ & $10.69 \sim 20.43$ & $5.67 \sim 68.04$ & $2.47 \sim 67.67$ \\
$b_{\mathrm{b}}(440 \mathrm{~nm})$ & $0.22 \sim 0.54$ & $0.25 \sim 0.43$ & $0.09 \sim 0.49$ & $0.12 \sim 0.74$ \\
$B(440 \mathrm{~nm})$ & $0.012 \sim 0.028$ & $0.015 \sim 0.034$ & $0.004 \sim 0.068$ & $0.005 \sim 0.073$ \\
$C(532 \mathrm{~nm})$ & $3.89 \sim 43.85$ & $8.98 \sim 27.38$ & $5.58 \sim 53.28$ & $2.54 \sim 57.43$ \\
$b(532 \mathrm{~nm})$ & $3.33 \sim 39.51$ & $8.57 \sim 17.38$ & $5.10 \sim 61.03$ & $2.24 \sim 64.53$ \\
$b_{\mathrm{b}}(532 \mathrm{~nm})$ & $0.19 \sim 0.25$ & $0.15 \sim 0.22$ & $0.071 \sim 0.24$ & $0.10 \sim 0.29$ \\
$B(532 \mathrm{~nm})$ & $0.006 \sim 0.027$ & $0.008 \sim 0.025$ & $0.004 \sim 0.044$ & $0.003 \sim 0.048$ \\
$S_{\mathrm{c}}$ & $-1.46 \sim 0.82$ & $-1.52 \sim-0.73$ & $-1.40 \sim-0.59$ & $-1.57 \sim-0.42$ \\
$S_{\mathrm{b}}$ & $-0.91 \sim-0.31$ & $-1.28 \sim-0.49$ & $-1.12 \sim-0.48$ & $-1.39 \sim-0.40$ \\
$S_{\mathrm{bb}}$ & $-3.15 \sim-1.55$ & $-3.06 \sim-1.82$ & $-3.26 \sim-1.37$ & $-3.51 \sim-1.40$
\end{tabular}

IOP, inherent optical property; $N$, number of collection points; $\mathrm{C}(440 \mathrm{~nm})$, attenuation coefficient at $532 \mathrm{~nm} ; \mathrm{b}(440 \mathrm{~nm})$, scattering coefficient at 440 $\mathrm{nm} ; \mathrm{b}_{b}(440 \mathrm{~nm})$, backscattering coefficient at $440 \mathrm{~nm} ; \mathrm{B}(440 \mathrm{~nm})$, backscattering ratio at $440 \mathrm{~nm} ; C(532 \mathrm{~nm})$, attenuation coefficient at $53 \mathrm{~nm} ; \mathrm{b}(532 \mathrm{~nm})$, scattering coefficient at $532 \mathrm{~nm} ; \mathrm{bb}(532 \mathrm{~nm})$, backscattering coefficient at $532 \mathrm{~nm} ; \mathrm{B}(532 \mathrm{~nm})$, backscattering ratio at $532 \mathrm{~nm} ; \mathrm{S}_{c}$ spectral shape of the attenuation coefficients; $\mathrm{S}_{b}$, spectral shape of the scattering coefficient; $\mathrm{S}_{b b}$, spectral shape of the backscattering coefficient. 
$\rho^{\prime}(\lambda)=a_{\mathrm{sol}}^{*}(\lambda) C_{1} d$

where

$\rho^{\prime}(\lambda)$ is process variable, no specify physical significance. $a^{*}{ }_{\text {sol }}(\lambda)$ is the intracellular chlorophyll-specific absorption coefficient;

$C_{\mathrm{I}}$ is the intracellular chl-a concentration;

$d$ is the phytoplankton cell diameter.

The $a_{\text {sol }}^{*}(\lambda)$ coefficient of chl-a was 0.0201 at $675 \mathrm{~nm}$, as given in Bidigare et al. (1990). $Q_{\mathrm{a}}^{\prime}(\lambda)$ was calculated by following the method of Le et al. (2009). Fig. 3 presents $a_{\mathrm{ph}}(\lambda)$ in comparison with chl-a before and after the package effect was corrected. The package effect caused by high $C_{\text {chl-a }}$ destroys the correlation between the pigment absorption coefficient at $675 \mathrm{~nm}\left[a_{\mathrm{ph}}(675 \mathrm{~nm})\right]$ and $C_{\mathrm{chl}-\mathrm{a}}$ (Fig. 3A,B, and B'). The coefficient determined between $a_{\mathrm{ph}}(675 \mathrm{~nm})$ and $C_{\mathrm{chl}-\mathrm{a}}$ after the package effect correction was significantly improved. The package effect is a primary influencing factor for the bio-optical model between $a_{\mathrm{ph}}(675 \mathrm{~nm})$ and chl-a in Taihu lake.

\section{Relationship between inherent optical properties and inorganic suspended matter}

The correlations between IOPs and ISM were examined as well. Fig. 4 A-D provides the attenuation coefficient at $532 \mathrm{~nm}[c(532 \mathrm{~nm})]$, the absorption coefficient at $440 \mathrm{~nm}\left[a_{\text {Total }}(440 \mathrm{~nm})\right]$, the scattering coefficient at $532 \mathrm{~nm}[b(532 \mathrm{~nm})]$, and the backscattering coefficient at $532 \mathrm{~nm}\left[b_{\mathrm{b}}(532 \mathrm{~nm})\right]$ of particles in comparison with ISM. Specific symbols were used to discriminate between the datasets of the four time series. Fig. 4 indicates that ISM is the main optically-active constituent in Taihu lake. The resuspended sediment dramatically increases the ratio of ISM to TSM. The highest percentage of ISM to TSM can reach up to $95 \%$, and the mean percentage of ISM can reach up to $65.21 \%$. ISM is the main contributor to the scattering and backscattering coefficients (Stramski et al., 2004; Snyder et al., 2008). Thus, the main optical property in Taihu lake is scattering. A single scattering ratio $[b(\lambda) / c(\lambda)]$ can reach up to 0.93 (mean value of all sample sites and wavelengths) (Fig. 4E, F).
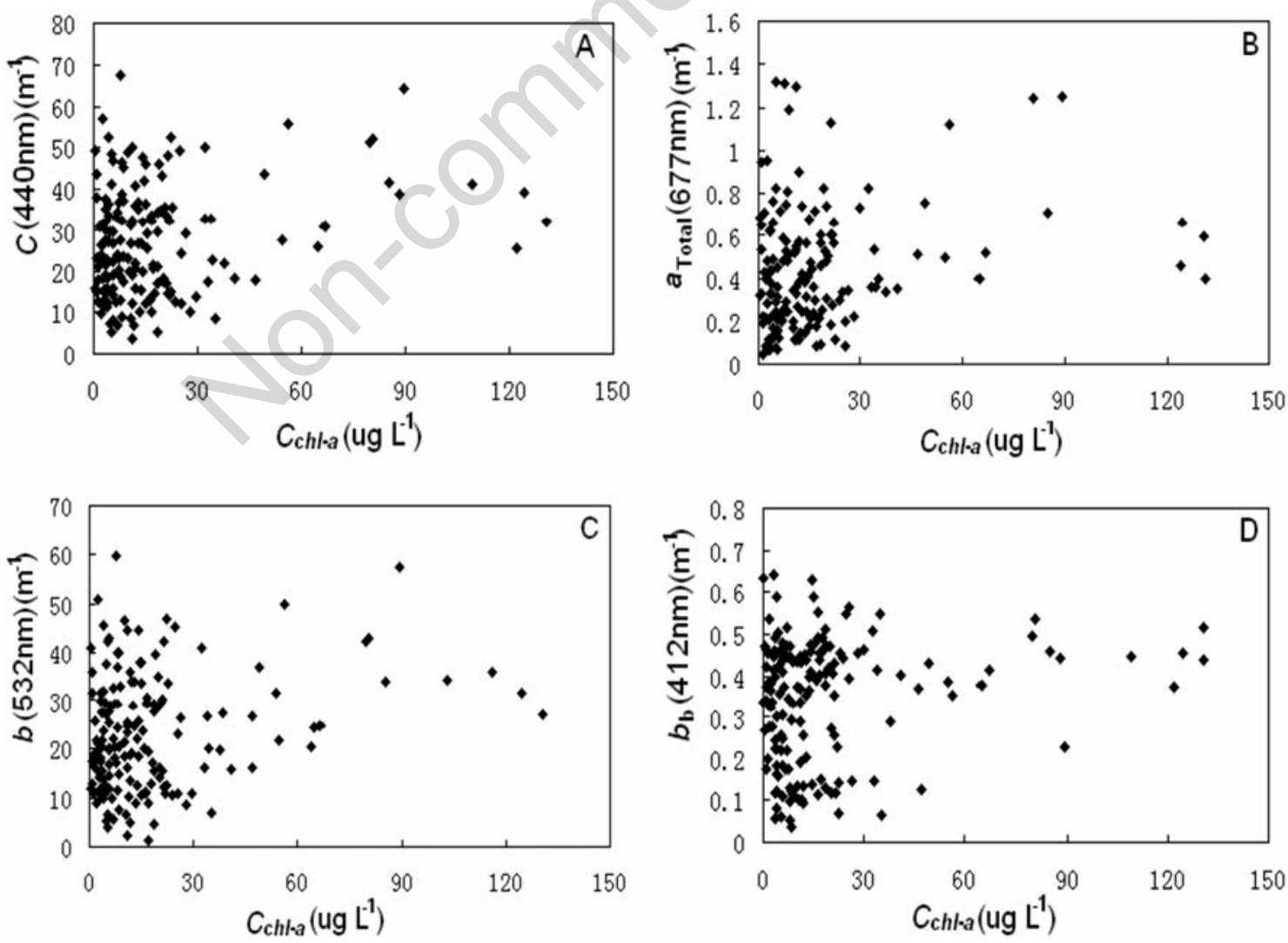

Fig. 2. Relationship between inherent optical properties and chlorophyll-a concentration: A) $C(440 \mathrm{~nm})-\mathrm{Cchl}-\mathrm{a}$; B) $a_{\text {Total }}(677 \mathrm{~nm})-\mathrm{Cchl}-\mathrm{a}$; C) $b(532 \mathrm{~nm})-\mathrm{Cchl}-\mathrm{a}$; and D) $b_{\mathrm{b}}(412 \mathrm{~nm})-\mathrm{Cchl}-\mathrm{a}$. 
Tab. 3 provides the relationships of the attenuation and scattering coefficients at $532 \mathrm{~nm}$ with ISM and the relationships of absorption at $440 \mathrm{~nm}$ with ISM. The $c(532$ $\mathrm{nm})\left(R^{2}=0.80, \mathrm{P}<0.0001, \mathrm{n}=213\right), b(532 \mathrm{~nm})\left(R^{2}=0.82\right.$, $\mathrm{P}<0.0001, \mathrm{n}=213)$, and $b_{\mathrm{b}}(532 \mathrm{~nm})\left(R^{2}=0.57, \mathrm{P}<0.0001\right.$, $\mathrm{n}=213)$ significantly increase with ISM. The $a_{\text {Total }}(440 \mathrm{~nm})$ $\left(R^{2}=0.61, \mathrm{P}<0.001, \mathrm{n}=213\right)$ also increases with it. Fig. 4B presents the scattering plot of $a_{\text {Total }}(440 \mathrm{~nm})$ with ISM. The correlations between $c(532 \mathrm{~nm}), b(532 \mathrm{~nm})$, and ISM are stronger than that between $a_{\text {Total }}(440 \mathrm{~nm})$ and ISM. This is because water constituents in inland water are independent of one another, and the absorption peak for chlorophyll may be found at $440 \mathrm{~nm}$. However, as a result of the temporal variations of the IOPs, the parameters and the correlation coefficients $\left(R^{2}\right)$ determined in each relationship between IOPs and ISM are significantly different (Tab. 3). In each function, the parameters, i.e. the slope, intercept, and $R^{2}$ of the function for $c(532 \mathrm{~nm}), a_{\text {Total }}(440$ $\mathrm{nm}), b(532 \mathrm{~nm})$, and $b_{\mathrm{b}}(532 \mathrm{~nm})$ with ISM at each time series, were compared with one another. The variation coefficient (VC) of the slope, intercept, and $R^{2}$ in each relationship was as follows:

$c(532 \mathrm{~nm})$ with ISM:VC of slope $=0.14$;

$\mathrm{VC}$ of intercept $=0.12$; $\mathrm{VC}$ of $R^{2}=0.10$ );

$b(532 \mathrm{~nm})$ with ISM: VC of slope $=0.2$;

$\mathrm{VC}$ of intercept $=0.12$; $\mathrm{VC}$ of $R^{2}=0.11$ );

$a_{\text {Total }}(440 \mathrm{~nm})$ with ISM: VC of slope $=0.53$;

$\mathrm{VC}$ of intercept $=0.49$; $\mathrm{VC}$ of $R^{2}=0.23$.

As it is manifest, VCs for $c(532 \mathrm{~nm})$ and $b(532 \mathrm{~nm})$ with ISM were much smaller than that for $a_{\text {Total }}(440 \mathrm{~nm})$ with ISM. This implies that the temporal variations of the $c(532 \mathrm{~nm})$ and $b(532 \mathrm{~nm})$ influencing factors are smaller than the $a_{\text {Total }}(440 \mathrm{~nm})$ influencing factors. Therefore, the functions for $c(532 \mathrm{~nm})$ and $b(532 \mathrm{~nm})$ with ISM are more valid compared to $a_{\text {Total }}(440 \mathrm{~nm})$ with ISM. The backscattering coefficient was highly determined by ISM for its high refractive index. Thus, owing to the different physicochemical properties of water constituents at each time series, the variation coefficients of slope, intercept, and $R^{2}$ for $b_{\mathrm{b}}(532 \mathrm{~nm})$ with ISM are $0.20,0.38$, and 0.02 , respectively. The $R^{2}$ of each function for $b_{\mathrm{b}}(532 \mathrm{~nm})$ with ISM at different time series is very high (2006-11:0.80; 2007-3: 0.84; 2007-11: 0.82; 2008-11: 0.85$)$. In contrast, the $R^{2}$ of function for $b_{\mathrm{b}}(532$ $\mathrm{nm})(0.5723)$ with ISM for all the sampling points is very small. This indicates that the relationship between $b_{\mathrm{b}}(532 \mathrm{~nm})$ and ISM is valid at each time series, while it is not valid for all the sampling points. Consequently, different functions should be used to describe the relationship between $b_{\mathrm{b}}(532 \mathrm{~nm})$ and ISM.
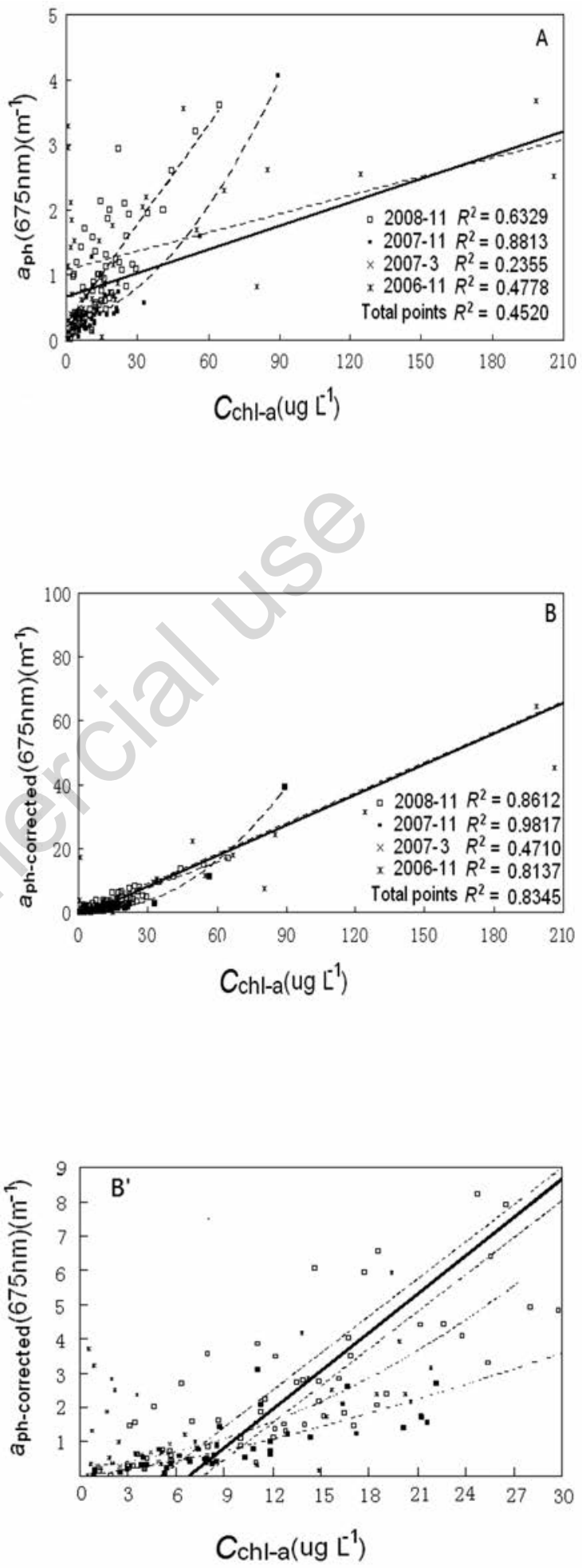

Fig. 3. Relationship between $a_{\mathrm{ph}}(675 \mathrm{~nm})$ and chl-a A) before and $\mathrm{B}$ ) after the package effect correction. $\mathrm{R}^{2}$ is the coefficient of determination and it indicates the significance of the trend. B') zooms in part of figure B, precisely the area where $a_{\text {ph-corrected }}$ $(675 \mathrm{~nm})$ is $1-9 \mathrm{~m}^{-1}$ and chl-a is $0-30 \mathrm{ug} \mathrm{L}^{-1}$. Dashed lines are the trend curves of each year, while the real line is the trend curve of the total data. 
The variation of diffuse attenuation coefficient of particles with chlorophyll-a concentration and organic suspended matter

The apparent optical property (AOP) (diffuse attenuation coefficient of particle, $K_{\text {dbio }}$ ) was expressed by the main optical active constituent in Case 1 water (refferred to as phytoplankton dominant clear water) to study the bio-optical properties of oceanic waters (Gordon, 1987; Morel and Maritorena, 2001; Morel et al. 2007). Although various parameterisations of $K_{\text {dbio }}$ have been proposed in previous studies, all its functions were parameterised by
$C_{\text {chl-a. }}$. Being Taihu lake a typical inland shallow lake, the composition of its water constituents is significantly affected by terrigenous and resuspended sediment. Thus, in the study, the traditional main optically-active constituent $\left(C_{\text {chl-a }}\right)$ was replaced by ISM in order to extend the previous idea that $K_{\mathrm{dbio}}$ can be expressed by the main opticallyactive component to Taihu lake and to confirm the main optically-active constituent. The relationships between $K_{\mathrm{dbio}}(675 \mathrm{~nm})$ and $C_{\mathrm{chl-a}}($ Fig. $5 \mathrm{~A})$ and the relationship between $K_{\text {dbio }}(440 \mathrm{~nm})$ and OSM were detected (Fig. 5B). The poor relationship of $K_{\mathrm{dbio}}(440 \mathrm{~nm})$ and $K_{\mathrm{dbio}}(675 \mathrm{~nm})$ with $C_{\text {chl-a }}$ and OSM was also explored. Total OSM sig-
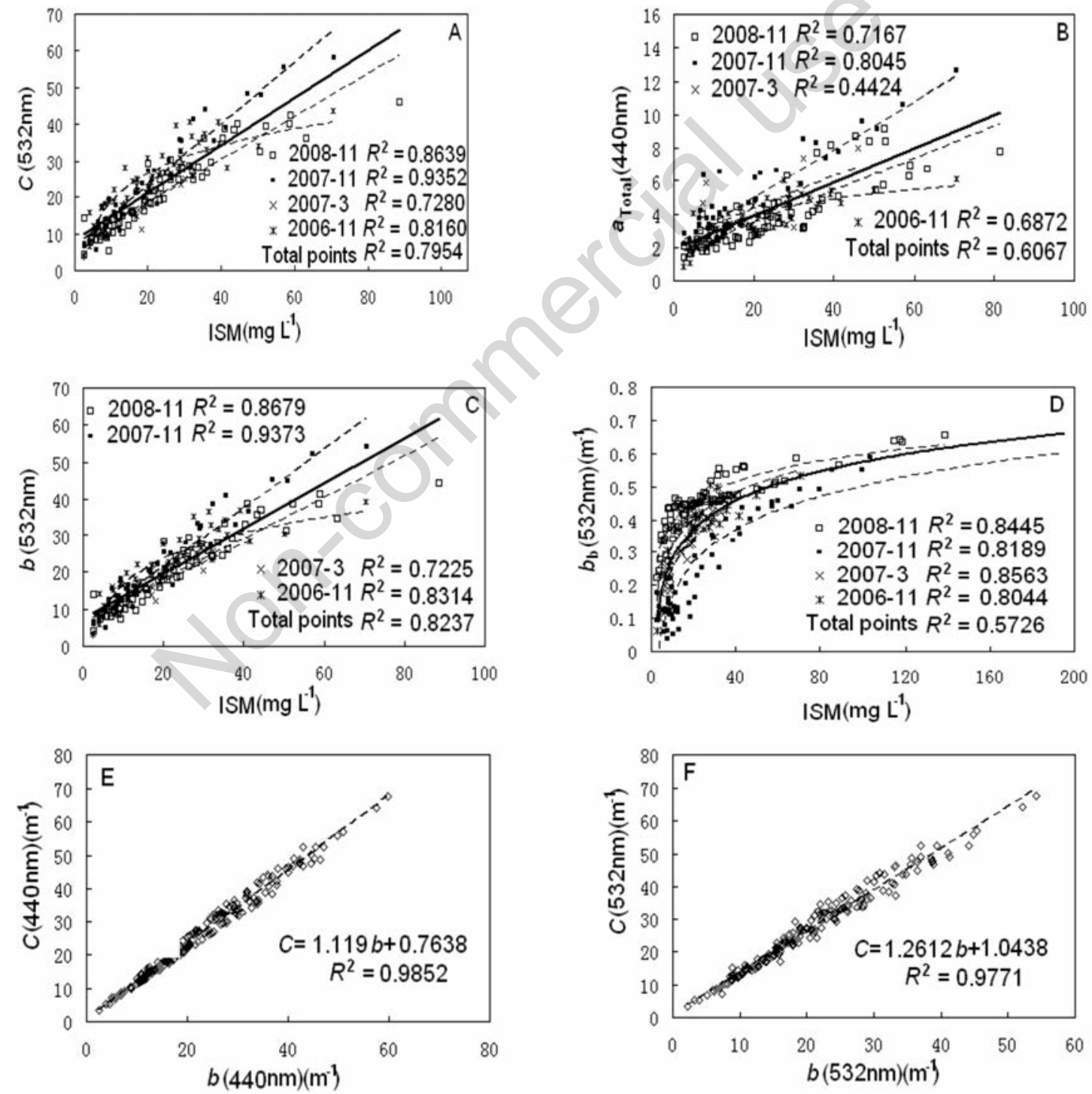

Fig. 4. A-D) provide the relationship between inherent optical properties and inorganic suspended matter: A) C(532nm)-ISM; B) $a_{\text {Total }}(440 \mathrm{~nm})-I S M$; C) $b(532 \mathrm{~nm})-I S M$; D) $b_{\mathrm{b}}(532 \mathrm{~nm})-I S M$. Dashed lines are the trend curves of each year, while the real line is the trend curve of the total data. $R^{2}$ is the coefficient of determination and it indicates the significance of the trend. E) and F) show the relationship between scattering and attenuation coefficient at $440 \mathrm{~nm}(\mathrm{E})$ and at $532 \mathrm{~nm}(\mathrm{~F})$. The dashed line is the trend curve. 
nificantly correlates with $C_{\text {chl-a }}\left(\mathrm{P}<0.0001, R^{2}=0.88\right.$, including the point in the ellipse; $\mathrm{P}<0.005, R^{2}=0.63$, excluding the point in the ellipse) (Fig. 5C). Thus, phytoplankton debris is the primary component of OSM but is not the primary contributor to $K_{\text {dbio }}$. This is similar to results in previous studies on Taihu lake (Zhang et al., 2004a, 2004b).

\section{The diffuse attenuation coefficient of particle variation with inorganic and total suspended matter}

ISM is the primary component of TSM (mean percentage of ISM for all sample points is $65 \%, \mathrm{SD}=0.19$ ) (Fig. 6C). This is mainly caused by the resuspended sediments. Consequently, ISM is taken into account as an important optically-active component to describe the biooptical properties in Taihu lake. The relationship between $K_{\text {dbio }}$ and ISM and TSM was determined (Fig. 6 A,B) and out of it some remarkable linear functions were found:

$K_{\text {dbio }}(532)=0.094 \mathrm{ISM}+1.51, \mathrm{~N}=227, R^{2}=0.84$,

Predicted $\mathrm{RMSE}=12.5$

(eq. 15)

where

0.094 can be treated as the specific diffuse attenuation coefficient of ISM at $532 \mathrm{~nm}$;

1.51 could be the contribution of OSM and CDOM at 532 nm to the $K_{\text {dbio }}$;

RMSE is the Root Mean Square Error.
$K_{\text {dbio }}(532)=0.062 \mathrm{TSM}+1.38, \mathrm{~N}=227, R^{2}=0.63$, Predicted $\mathrm{RMSE}=17.5$

(eq. 16)

where

0.062 can be treated as the specific diffuse attenuation coefficient of TSM at $532 \mathrm{~nm}$;

1.38 could be the contribution of CDOM at $532 \mathrm{~nm}$ to the $K_{\text {dbio }}$;

RMSE is the Root Mean Square Error.

The regressive result between $K_{\mathrm{dbio}}$ and TSM is not as good as that between $K_{\mathrm{dbio}}$ and ISM. This is because OSM hinders the stability of the regressive function for $K_{\mathrm{dbio}}$ and TSM (the departure from linearity between $K_{\mathrm{dbio}}$ and TSM is expressed by a large percentage of OSM; sample points are in the ellipse in Fig. 6B). The linear parameters in equation (15) are very close to the laboratory experiment results in the study by Zhang et al. (2004b).

\section{Separate regression analyses of inorganic and organic suspended matter for $K_{\mathrm{dbio}}$ at wavelength $\lambda$}

According to its linear additive rule, $K_{\mathrm{dbio}}(\lambda)$ can be expressed as:

$K_{\text {dio }}(\lambda)=K_{\mathrm{dISM}}^{*}(\lambda) * C_{\mathrm{ISM}}+K_{\mathrm{dOSM}}^{*}(\lambda) * C_{\mathrm{OSM}}$

where

Tab. 3. Regressive equations between inherent optical propertiesand inorganic suspended matter.

\begin{tabular}{|c|c|c|c|c|}
\hline IOP & Date & Equation & $R^{2}$ & $\mathrm{~N}$ \\
\hline$c(532 \mathrm{~nm})$ & $\begin{array}{c}2006-11 \\
2007-03 \\
2007-11 \\
2008-11 \\
\text { Total points }\end{array}$ & $\begin{array}{l}c(532 \mathrm{~nm})=13.60 \mathrm{Ln}(\mathrm{ISM})-8.2302 \\
c(532 \mathrm{~nm})=0.68 \mathrm{ISM}+8.6318 \\
c(532 \mathrm{~nm})=0.96 \mathrm{ISM}+8.1949 \\
c(532 \mathrm{~nm})=0.79 \mathrm{ISM}+7.42 \\
c(532 \mathrm{~nm})=0.81 \mathrm{ISM}+9.8466\end{array}$ & $\begin{array}{l}0.82 \\
0.73 \\
0.94 \\
0.87 \\
0.80\end{array}$ & $\begin{array}{c}64 \\
15 \\
66 \\
68 \\
213\end{array}$ \\
\hline$a_{\text {Total }}(440 \mathrm{~nm})$ & $\begin{array}{l}2006-11 \\
2007-03 \\
2007-11 \\
2008-11 \\
\text { Total points }\end{array}$ & $\begin{array}{l}a_{\text {Total }}(440 \mathrm{~nm})=2.81 \mathrm{Ln}(\mathrm{ISM})+0.0581 \\
a_{\text {Total }}(440 \mathrm{~nm})=0.29 \mathrm{ISM}+0.5111 \\
a_{\text {Total }}(440 \mathrm{~nm})=0.14 \mathrm{ISM}+2.0429 \\
a_{\text {Total }}(440 \mathrm{~nm})=0.10 \mathrm{ISM}+1.54 \\
a_{\text {Total }}(440 \mathrm{~nm})=0.13 \mathrm{ISM}+2.2946\end{array}$ & $\begin{array}{l}0.69 \\
0.45 \\
0.81 \\
0.72 \\
0.61\end{array}$ & $\begin{array}{c}64 \\
15 \\
66 \\
68 \\
213\end{array}$ \\
\hline$b(532 \mathrm{~nm})$ & $\begin{array}{c}2006-11 \\
2007-03 \\
2007-11 \\
2008-11 \\
\text { Total points }\end{array}$ & $\begin{array}{l}b(532 \mathrm{~nm})=10.35 \mathrm{Ln}(\text { ISM })-7.5162 \\
b(532 \mathrm{~nm})=0.52 \text { ISM }+6.8563 \\
b(532 \mathrm{~nm})=0.80 \text { ISM }+5.612 \\
b(532 \mathrm{~nm})=0.56 \text { ISM }+6.8908 \\
b(532 \mathrm{~nm})=0.61 \text { ISM }+7.4664\end{array}$ & $\begin{array}{l}0.84 \\
0.73 \\
0.94 \\
0.87 \\
0.83\end{array}$ & $\begin{array}{c}64 \\
15 \\
66 \\
68 \\
213\end{array}$ \\
\hline$b_{\mathrm{b}}(412 \mathrm{~nm})$ & $\begin{array}{c}2006-11 \\
2007-03 \\
2007-11 \\
2008-11 \\
\text { Total points }\end{array}$ & $\begin{array}{l}b_{\mathrm{b}}(412 \mathrm{~nm})=0.12 \operatorname{Ln}(\text { ISM })+0.0314 \\
b_{\mathrm{b}}(412 \mathrm{~nm})=0.14 \operatorname{Ln}(\text { ISM })-0.0718 \\
b_{\mathrm{b}}(412 \mathrm{~nm})=0.15 \operatorname{Ln}(\text { ISM })-0.1727 \\
b_{\mathrm{b}}(412 \mathrm{~nm})=0.09 \operatorname{Ln}(\text { ISM })+0.1838 \\
b_{\mathrm{b}}(412 \mathrm{~nm})=0.12 \operatorname{Ln}(\text { ISM })+0.0085\end{array}$ & $\begin{array}{l}0.81 \\
0.84 \\
0.82 \\
0.85 \\
0.58\end{array}$ & $\begin{array}{c}64 \\
15 \\
66 \\
68 \\
213\end{array}$ \\
\hline
\end{tabular}

IOP, inherent optical property; $\mathrm{R}^{2}$, coefficient of determination; $N$, number of collection points; c (532nm), attenuation coefficient at $532 \mathrm{~nm}$; $\mathrm{a}_{\text {Total }}(440 \mathrm{~nm})$, absorption coefficients at $440 \mathrm{~nm} ; \mathrm{b}(532 \mathrm{~nm})$, scattering coefficient at $532 \mathrm{~nm} ; \mathrm{b}_{b}(412 \mathrm{~nm})$, backscattering coefficient at $412 \mathrm{~nm} ; \mathrm{ISM}$, inorganic suspended matter. 

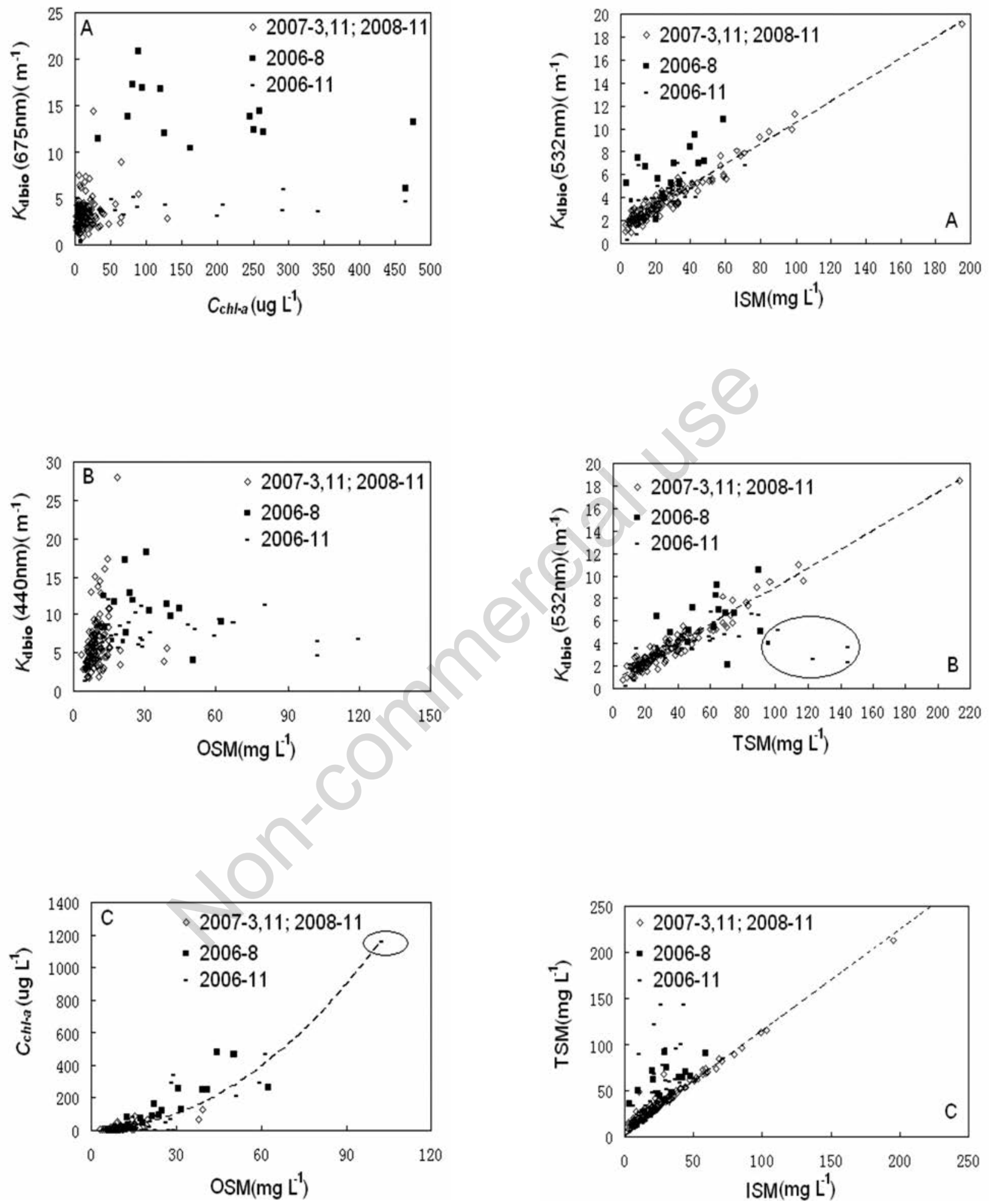

Fig. 5. Scattering plot of the $K_{\text {dbio }}$ values for the upper layer as a function of A) $C_{\mathrm{chl}-\mathrm{a}}$ and B) OSM. C) is the scattering plot of $C_{\text {chl-a }}$ and OSM. The trend curve of $C_{\text {chl-a }}$ to OSM is represented by adashed line (when $\mathrm{P}<0.0001, R^{2}=0.8831$, the point in the ellipse is included; when $\mathrm{P}<0.005, R 2=0.6308$, the point in the ellipse is excluded).

Fig. 6. Scattering plot of the $K_{\text {dbio }}$ values for the upper layer as a function of A) ISM and B) TSM. In B) the point in the ellipse shows a high percentage of OSM. C) is the scattering plot of TSMand ISM. In A-C) dashed lines are the trend curves. 

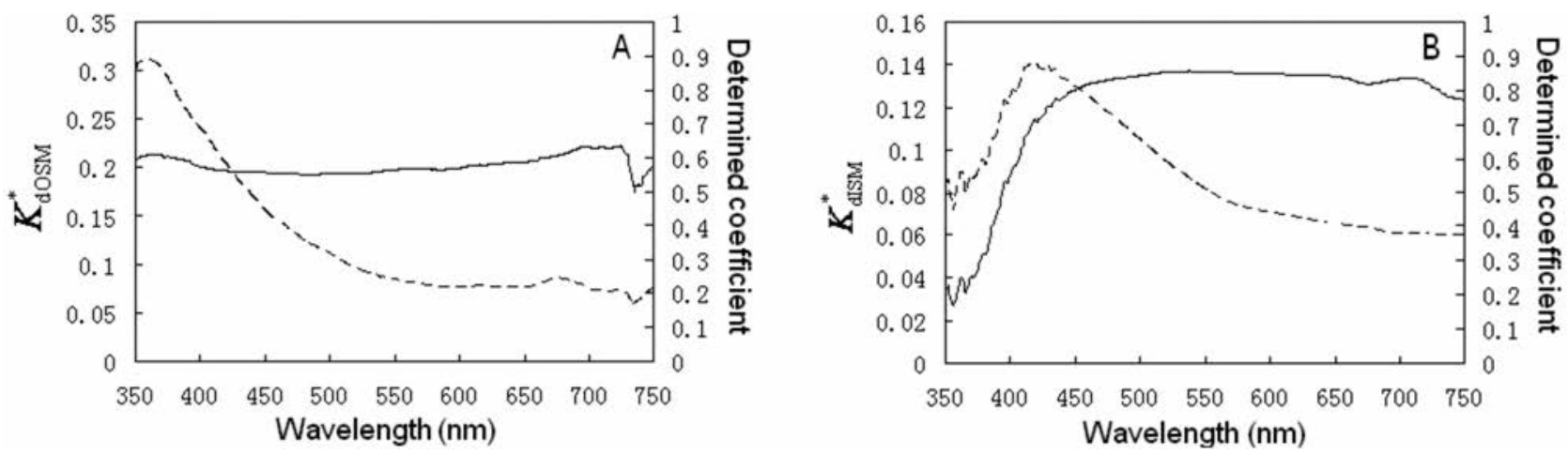

Fig. 7. Specific diffuse attenuation coefficient of A) organic and B) inorganic particles. In A) and B) the average specific diffuse attenuation coefficient is represented by a dashed line, while the determined coefficient by a real line.

$K_{\mathrm{dISM}}^{*}(\lambda)$ is the specific diffuse attenuation coefficient of inorganic particles;

$C_{\text {ISM }}$ is the concentration of ISM;

$K_{\text {dOSM }}^{*}(\lambda)$ is the specific diffuse attenuation coefficient of organic particles;

$C_{\mathrm{OSM}}$ is the concentration of OSM.

Equation (17) can be used to derive the average specific diffuse attenuation coefficient of organic and inorganic particles in Taihu lake. First, the $K_{\text {dbio }}(\lambda)$ values at each wavelength are divided by $C_{\mathrm{OSM}}$ ( or $\left.C_{\mathrm{ISM}}\right)$. Second, a linear regression $\left(R^{2} \geq 0.60, \quad \mathrm{P}<0.005\right)$ between $K_{\mathrm{dbio}}(\lambda) / C_{\mathrm{OSM}}$ [or $\left.K_{\mathrm{dbio}}(\lambda) / C_{\mathrm{ISM}}\right]$ and $C_{\mathrm{ISM}} / C_{\mathrm{OSM}}$ (or $C_{\mathrm{OSM}} / C_{\mathrm{ISM}}$ ) for each dataset is used to obtain the slope of line, [i.e., $K_{\mathrm{dISM}}^{*}(\lambda)$ and $K_{\mathrm{dOSM}}^{*}(\lambda)$ ] (Fig. 7). The spectral property of $K_{\mathrm{dOSM}}^{*}(\lambda)$ at approximately $675 \mathrm{~nm}$ indicates the chl-a absorption peak. Furthermore, the value of $K_{\mathrm{dOSM}}^{*}(\lambda)$ is much larger than the specific diffuse attenuation coefficient of chl-a $\left[K_{\text {dchl-a }}^{*}(\lambda)\right]$ in previous studies (Smith and Baker, 1978; Morel, 1988; Mitchell and Holm-Hansen, 1991; Stambler et al., 1997; Figueroa, $2002)$. The spectral property of $K_{\mathrm{dISM}}^{*}(\lambda)$ in the $420-750$ $\mathrm{nm}$ range is smooth and similar to the scattering and absorption spectral properties of ISM. The $K_{\text {dISM }}^{*}(\lambda)$ at 532 $\mathrm{nm}$ is 0.0898 , i.e. it is approximately close to the slope of the linear function between $K_{\mathrm{dbio}}$ and ISM - 0.0942 - retrievable in equation 15 . The coefficient for $K_{\text {dISM }}^{*}$ determined in the $350-450 \mathrm{~nm}$ range is much lower. ISM has a low contribution to short wavelengths during absorption. Hence, the coefficient for $K_{\text {dosm }}^{*}$ determined over the whole wavelength range is very high. This is because the OSM absorption coefficient is very large at short wavelengths, and CDOM significantly correlates with OSM $\left(R^{2}=0.51, \mathrm{P}<0.005\right)$.

\section{CONCLUSIONS}

In conclusion, as an important optically-active constituent, ISM highly correlates with IOPs and significantly determines the underwater light field $\left(K_{\text {dbio }}\right)$ in Taihu lake. On the basis of the present data, the following conclusions can be drawn. First, the active optical factor in Case 1 water (chl-a) is replaced by ISM in the Taihu lake water and in it IOPs are more sensitive to ISM. Second, the IOPs significantly correlate with ISM, and the equation parameters of the present data do not differ significantly from each other at different cruises, particularly for the function of $c(532 \mathrm{~nm})$ and $b(532 \mathrm{~nm})$ with ISM. Thus, the parameters in the models are valid. Third, the diffuse attenuation coefficient is significantly affected by ISM and linearly correlates with it. The specific diffuse attenuation coefficients of organic and inorganic particles are different, especially in the wavelength range of $350-450 \mathrm{~nm} . K_{\text {dOSM }}^{*}(\lambda)$, which includes the chl-a absorption property at $675 \mathrm{~nm}$, is larger than $K_{\text {dISM }}^{*}(\lambda)$. Hence, the attenuation ability of OSM is stronger than that of ISM.

\section{ACKNOWLEDGMENTS}

This research was supported by the National Natural Science Funds of China (41201325; 41030751; $41271343 ; 41103047 ; 40901174)$, the Initial funding of Nanjing Normal university (2011105XGQ0244), Natural Science Funds of Provincial Universities (12KJB170005), the Project Funded by the Priority Academic Program Development of Jiangsu Higher Education Institutions.

The authors would like to thank the two anonymous reviewers for their useful comments and suggestions. 


\section{REFERENCES}

Aas E, 1981. The refractive index of phytoplankton. Department of Geophysics, Oslo University: $61 \mathrm{pp}$.

Arbones B, Figueiras FG, Zapata M, 1996. Determination of phytoplankton absorption coefficient in natural seawater samples: evidence of a unique equation to correct the path length amplification on glass-fiber filters. Mar. Ecol. Prog. Ser. 137:293-304.

Bachmann RW, Hoyer MV, Canfield DE, 2000. The potential for wave disturbance in shallow Florida lakes. Lake Reserv. Manage.16:281-291.

Baker KS, Smith RC, 1982. Bio-optical classification and model of natural waters 2. Limnol. Oceanogr. 27:500-509.

Bernard S, Probyn TA, Barlow RG, 2001. Measured and modeled optical properties of particulate matter in the southern Benguela. S. Afr. J. Sci. 97:410-420.

Bidigare RR, Ondrusek ME, Morrow JH, 1990. In vivo absorption properties of algal pigments. Proc. SPIE, P. Soc. PhotoOpt. Ins.1032:290-302.

Boss E, Pegau WS, 2001. Relationship of light scattering at an angle in the backward direction to the backscattering coefficient. Appl. Optics 40:5503-5507.

Boss E, Twardowski MS, Herring S, 2001. Shape of the particulate beam attenuation spectrum and its inversion to obtain the shape of the particulate size distribution. Appl.Optics 40:4885-4893.

Bricaud A, Babin M, 1995. Variability in the chlorophyll-specific absorption coefficients of natural phytoplankton: analysis and parameterization. J. Geophys. Res. 7:13321-13332.

Bricaud A, Morel A, Babin M, 1998.Variations of light absorption by suspended particles with chlorophyll a concentration in oceanic (case 1) waters: analysis and implications for biooptical models. J. Geophys. Res. 103:31033-31044.

Bricaud A, Morel A, Prieur L, 1981. Absorption by dissolved organic matter in the sea (yellow substance) in the UV and visible domain. Limnol. Oceanogr. 26:43-53.

Bricaud A, Roesler C, Parslow J, 2002. Bio-optical studies during the JGOFS-Pacific program: a contribution to the knowledge of the equatorial system. Deep-Sea Res. Pt. II 49:2583-2599.

Bricaud A, Stramski D, 1990. Spectral absorption coefficients of living phytoplankton and nonalgal biogenous matter: acomparison between the Peru upwelling area and the Sargasso Sea. Limnol. Oceanogr. 35:562-582.

Carder KL, Hawes SK, Baker KA, 1991. Reflectance model for quantifying chlorophyll a in the presence of productivity degradation products. J. Geophys. Res. 96:20599-20611.

Chen WM, Chen KN, Hu YH, 2006. Discussion on possible error for phytoplankton chlorophyll-a concentration analysis using hot-ethanol extraction method. J. Lake Sci. 18:550-552.

Cleveland JS, Weidemann AD, 1993. Quantifying absorption by aquatic particles: a multiple scattering correction for glassfiber filters. Limnol. Oceanogr. 38:1321-1327.

Darecki M, Stramski D, 2004. An evaluation of MODIS and Sea-WiFS bio-optical algorithms in the Baltic Sea. Remote Sens. Environ. 89:326-350.

Dickey T, Granata T, Marra J, 1993. Seasonal variability of biooptical and physical properties in the Sargasso Sea. J. Geophys. Res.-Oceans. 98:865-898.

Figueroa FL, 2002. Bio-optical characteristics of Gerlache and
Brans field Strait waters during an Antarctic summer cruise. Deep-Sea Res. Pt. II. 49:675-691.

Gordon HR, 1987. Bio-optical model describing the distribution of irradiance at the sea surface resulting from a point source embedded in the ocean. Appl. Optics 26:4133-4148.

Gordon HR, Morel A, 1983. Remote assessment of ocean color for interpretation of satellite visible imagery: a review. Springer-Verlag, Berlin: 114 pp.

Gould RW Jr., Arnone RA, Martinolich MP, 1999. Spectral dependence of the scattering coefficient in case 1 and case 2 waters. Appl. Optics 38:2377-2383.

Green S, Blough N, 1994. Optical absorption and fluorescence properties of chomophoric dissolved organic matter in natural waters. Limnol. Oceanogr. 39:1903-1916.

Hoepffner N, Sathyendranath S, 1992. Bio-optical characteristics of coastal waters: absorption spectra of phytoplankton and pigment distribution in the western North Atlantic. Limnol. Oceanogr. 37:1660-1679.

Hoepffner N, Sathyendranath S, 1993. Determination of major groups of phytoplankton pigments from the absorption spectra of total particulate matter.J. Geophys. Res.12:22789-22803.

Huang CC, Li YM, Wang Q, Sun DY, Le CF, Shi K, 2012. Scattering spectrum properties and their relationship to biogeochemical parameters: a case study in Taihu lake. Limnology 13:1-11.

Jerlov NG, 1976. Marine Optics, 2nd edition. Elsevier, New York.

Keith DJ, Yoder JA, Freeman SA, 2002. Spatial and temporal distribution of colored dissolved organic matter (CDOM) in Narragansett Bay, Rhode Island: implications for phytoplankton in coastal waters. Estuar. Coast. Shelf S. 55:705-717.

Le CF, Li YM, Zha Y, 2009. Specific absorption coefficient and the phytoplankton package effect in lake Taihu, China. Hydrobiologia 619:27-37.

Loisel H, Morel A, 1998. Light scattering and chlorophyll concentration in case 1 waters: A reexamination. Limnol. Oceanogr. 43:847-858.

Mitchell BG, 1990. Algorithms for determining the absorption coefficient of aquatic particulates using the quantitative filter technique (QFT). Proc. SPIE, P. Soc. Photo-Opt. Ins. 1302:137-148.

Mitchell BG, Holm-Hansen O, 1991. Bio-optical properties of Antarctica peninsula waters: differentiation from temperature ocean models. Deep-Sea Res. Pt. II. 38:1009-1028.

Mitchell BG, Keifer DA, 1984. Determination of absorption and fluorescence excitation spectra for phytoplankton, p. 157169. In: O. Holm-Hansen, L. Bolis, R. Giles (eds.), Marine phytoplankton and productivity. Springer-Verlag, Berlin.

Mitchell BG, Kiefer DA, 1988. Chlorophyll a specific absorption and fluorescence excitation spectra for light limited phytoplankton. Deep-Sea Res. 35:639-663.

Moore C, Barnard A, Hankins D, 2004. Spectral absorption and attenuation meter (ac-s) user's guide revision A. America. WET Labs. Inc., Philomath, OR, USA: p. 5-20.

Morel A, 1974. Optical properties of pure water and pure seawater, p. 1-24. In: N.G. Jerlov and E. Steeman (eds.), Optical aspects of oceanography. Academic Press, New York.

Morel A, 1988. Optical modelling of the upper ocean in relation to its biogenous matter content (case 1 waters). J. Geophys. Res. 93:10749-10768.

Morel A, 2009. Are the empirical relationships describing the 
bio-optical properties of case 1 waters consistent and internally compatible? J. Geophys. Res. 114:1-15.

Morel A, Ahn YH, 1990. Optical efficiency factors of free-living marine bacteria: influence of bacterioplankton upon the optical properties and particulate organic carbon in oceanic waters. J. Mar. Res. 48:145-175.

Morel A, Belanger S, 2006. Improved detection of turbid waters from ocean color information. Remote Sens. Environ. 102:237-249.

Morel A, Bricaud A, 1981. Theoretical results concerning light absorption in a discrete medium, and application to specific absorption of phytoplankton. Deep-Sea Res. 28:1375-1393.

Morel A, Bricaud A, 1991. Inherent optical properties of algal cells including picoplankton: theoretical and experimental results. University Pierre et Marie Curie-CNRS, Paris, France.

Morel A, Claustre H, Antoine D, Gentili B, 2007. Natural variability of bio-optical properties in Case 1 waters: attenuation and reflectance within the visible and near-UV spectral domains, as observed in South Pacific and Mediterranean waters. Biogeosciences 4:913-925.

Morel A, Gentili B, Chami M, 2006. Bio-optical properties of high chlorophyll Case 1 waters, and of yellow-substance dominated Case 2 waters. Deep-Sea Res. Pt. I53:1439-1559.

Morel A, Maritorena S, 2001. Bio-optical properties of oceanic waters: a reappraisal. J. Geophys. Res. 106:7163-7180.

Pegau S, Zaneveld JRV, Mitchell BG, Mueller JL, Kahru M, Wieland J, Stramska M, 2003. Ocean optics protocols for satellite ocean color sensor validation. Revision 4, Volume IV: Inherent optical properties: instruments, characterizations, field measurements and dataanalysis protocols. In: J. L. Mueller, G. S. Fargion and C. R. McClain (eds.), NASA Tech. Memo. 2003 - 211621/Rev4, vol. IV. NASA Publ., Goddard Space Flight Space Center, Greenbelt.

Platt T, 1986. Primary production of the ocean water column as a function of surface light intensity, algorithms for remote sensing. Deep-Sea Res.33:149-163.

Platt T, Caverhill CM, Sathyendranath S, 1991. Basin-scale estimates of oceanic primary production by remote sensing: the North Atlantic. J. Geophys. Res. 96:15147-15159.

Platt T, Sathyendranath S, 1988. Oceanic primary production: estimation by remote sensing at local and regional scales. Science 241:1613-1620.

Platt T, Sathyendranath S, White GN, 1990. Primary production by phytoplankton: analytic solutions for daily rates per unit area of water surface. P. Roy. Soc. Lond. B Bio. 241:101-111.

Pope R, Fry E, 1997. Absorption spectrum (380-700 nm) of pure waters: II. Integrating cavity measurements. Appl. Optics 36:8710-8723.

Qin BQ, Hu WP, Chen WM, 2004. The process and mechanism of water environment evolvement in lake Taihu. Science Press Publ., Beijing.

Semovski SV, 1999. The Baltic sea and lake Baikal underwater bio-optical fields simulation using ecodynamical model. Ecol. Model. 116:149-163.

Siegel DA, Westberry TK, O’Brien MC, 2001. Bio-optical modeling of primary production on regional scales: the Bermuda bio-optics project. Deep-Sea Res. Pt. II 48:1865-1896.

Smith RC, Baker KS, 1978. The bio-optical state of the ocean waters and remote sensing. Limnol. Oceanogr. 23:247-259.
Smith RC, Baker KS, 1981. Optical properties of the clearest natural waters. Appl. Optics 20:177-184.

Smith RC, Booth CR, Star JL, 1984. Oceanographic bio-optical profiling system. Appl. Optics 23:2791-2797.

Smith RC, Menzies DW, Booth CR, 1996. Oceanographic biooptical profiling system II. SPIE, P. Soc. Photo-Opt. Ins. 2963:777-789.

Snyder WA, Arnone RA, Davis CO, 2008. Optical scattering and backscattering by organic and inorganic particulates in U.S. coastal waters. Appl. Optics 47:666-677.

Song QJ, Tang JW, 2006. The study on the scattering properties in the Huanghai sea and East China sea. Acta Oceanol. Sin. 28:56-63.

Stambler N, Lovengreen C, Tilzer MN, 1997. The underwater light field in the Bellinghausen and Admudsen seas (Antarctica). Hydrobiologia 344:41-56.

Stramski D, Boss E, Bogucki D, 2004. The role of seawater constituents in light backscattering in the ocean. Prog. Oceanogr. 61:27-56.

Sullivan JM, Twardowski MS, Zaneveld JRV, Moore CM, Barnard AH, Donaghay PL, 2006. Hyperspectral temperature and salt dependencies of absorption by water and heavy water in the 400-750 nm spectral range. Appl. Optics 45:5294-5309

Sun DY, LiYM, Wang Q, 2009. Light scattering properties and their relation to the biogeochemical composition of turbid productive water: a case study of lake Taihu. Appl. Optics 48:1979-1989.

Twardowski MS, Boss E, MacDonald JB, 2001. Model for estimating bulk refractive index from the optical backscattering ratio and the implications for understanding particle composition in case I and case II waters. J. Geophys. Res. 14:129-42.

Wozniak B, Dera J, Koblenz-Mishke OJ, 1991. Modelling the relationship between primary production, optical properties, and nutrients in the sea. Proc. SPIE, P. Soc. Photo-Opt. Ins. 1750:246-275.

Wozniak B, Dera J, Semovski SV, Ostrowska M, Kaczmarek S, 1995. Modeling of Baltic primary production. Stud. Mater. Oceanol. 68:91-123.

Yentsch CS, 1962. Measurement of visible light absorption by particulate matter in the ocean. Limnol. Oceanogr. 7:207-217.

Zaneveld JRV, Kitchen JC, Moore C, 1994. The scattering error correction of reflecting-tube absorption meters. Proc. P. Soc. Photo-Opt. Ins. 2258:44-55.

Zaneveld JRV, Boss E, Barnard A, 2001. Influence of surface waves on measured and modeled irradiance profiles. Appl. Optics 40:1442-1449.

Zhang YL, Liu ML, Wang X, Zhu GW, Chen WM, 2009. Biooptical properties and estimation of the optically active substances in lake Tianmuhu in summer. Int. J. Remote Sens. 30:2837-2857.

Zhang YL, Qin BQ, Chen WM, 2004a. [Regression analysis of beam attenuation coefficient under water in lake Taihu]. [Article in Chinese]. Oceanol. Limnol. Sin. 35:209-213.

Zhang YL, Qin BQ, Chen WM, 2004b. [Experimental study on underwater light intensity and primary productivity caused by variation of total suspended matter]. [Article in Chinese]. Adv. Wat. Sci. 15:615-620. 